\title{
Small Step Frequency Changes Due to Footwear Condition Have No Effect on Running Economy
}

\section{(ㄷ)(ㄱ)(요 $\odot$}

\author{
Authors \\ Joe Warne ${ }^{1,4}$, Kieran Andrew Moran², Giles D Warrington ${ }^{3}$
}

\begin{abstract}
The aim of this study is to examine if small increases to step frequency associated with minimal footwear can influence Running Economy (RE). Twelve club-level runners with eight weeks of minimal footwear experience were recruited (age, $41 \pm 9$ years; stature, $177.2 \pm 10.4 \mathrm{~cm}$; body mass, $72.6 \pm 10.2 \mathrm{~kg}$; $\left.\dot{\mathrm{V}} \mathrm{O}_{2 \max }, 52.1 \pm 7.5 \mathrm{~mL} \cdot \mathrm{min}^{-1} \cdot \mathrm{kg}^{-1}\right)$. Two 6-min RE tests, one in minimal footwear and one in conventional running shoes were performed at $11 \mathrm{~km} \cdot \mathrm{h}^{-1}$. Two more 6 -min tests were completed during which step frequency was controlled using a metronome at the cadence of the opposite footwear condition ( $\left.\mathrm{RE}_{\text {revSF}}\right)$. Comparisons were completed between the same footwear using repeated measures ANCOVA. The increase in step frequency for minimal footwear vs. conventional running shoes was $7.3 \pm 2.3$ steps per minute ( $3.9 \%$ difference; $95 \% \mathrm{Cl}$ of difference [5.87 to 8.80 steps $/ \mathrm{min}$ ]; $p \leq 0.001$; Cohen's $d=0.70$ ). No significant differences were identified between RE and $R E_{\text {revSF }}$ for minimal footwear $(40.72 \pm 4.08$ vs. $41.09 \pm 4.19 \mathrm{~mL}$ - $\mathrm{min}^{-1} \cdot \mathrm{kg}^{-1} ; 95 \% \mathrm{Cl}$ of difference [-1.71 to 0.97$] ; \mathrm{p}=0.55$; Cohen's $d=0.09)$, or conventional running shoes $(42.04 \pm 4.68$ vs. $41.74 \pm 5.09 \mathrm{~mL} \cdot \mathrm{min}^{-1} \cdot \mathrm{kg}^{-1} ; 95 \% \mathrm{Cl}$ of difference $[-0.78$ to 1.37]; $p=0.55$; Cohen's $d=0.06)$. Small changes in step frequency $(\sim 4 \%)$ did not have any significant impact on RE.
\end{abstract}

Correspondence

Dr. Joe Warne

Institute of Technology Tallaght

Applied Science

Blessington Rd,

Dublin

Ireland

Tel.: + 353/861/039 917, Fax.: + 353/861/039 917

joe.warne@it-tallaght.ie

\section{Introduction}

Over the last ten years, renewed interest in more natural running footwear has seen the development of the minimalist footwear (MFW) sector. Minimalist footwear can be described as "providing minimal interference with the natural movement of the foot due to its high flexibility, low heel to toe drop, weight and stack height, and the absence of motion control and stability devices" [14]. Selfreport surveys have reported that $76 \%$ of runners in 2012 and $53 \%$ in 2014 have been interested in this novel footwear condition at some point [21,33], due to suggestions of improved performance and reduced injury risk, despite the fact that this has not yet been supported by consistent high-level evidence in the literature.

Whilst there are numerous purported benefits of running in minimalist shoes, perhaps the only consistent observation in the literature is an improvement in running economy $(\mathrm{RE})[3,13,24,31,32,36,42$, 43], which is supported by a recent systematic review [7]. RE can be described as the energy cost of running at a given submaximal, steadystate velocity [35], and is often reported as the oxygen cost of running 
[34]. RE has been shown to be the most reliable indicator of endurance performance in a similarly trained group of runners [22,23], explaining up to $65 \%$ of race performance over $10 \mathrm{~km}$ [10]. In addition, recent research has suggested $R E$ above the lactate threshold may be a reasonable predictor of $1500 \mathrm{~m}$ performance [39].

The improvements in RE reported in MFW have largely been associated with a reduced shoe mass when compared to conventional running shoes (CRS) $[7,13,14]$. However, the magnitude of improvement in RE cannot be explained by shoe mass alone [7] and may be attributed to a number of other variables. In this regard, it has been suggested that running biomechanics, which are consistently observed to change when switching to MFW [4, 24, 37], may also influence $\operatorname{RE}[11,16,31,44]$. One biomechanical variable that has received attention in this regard is step frequency. There is limited evidence that suggests increasing step (or stride) frequency can improve RE $[11,40]$. However, although somewhat dated research, increasing step frequency can also negatively influence RE $[6,20]$ or have no effect [26]. An increased step frequency has been well documented when running in minimalist footwear (MFW) when compared to CRS [24,41-43], and it is possible that this difference could influence RE. However, the natural changes to step frequency in relation to footwear type are typically small ( 2-4\%) [24, 41-43]. In addition, previous studies that have deliberately manipulated step frequency have done so at a greater magnitude (e. g. 8-10\%) [17, 20], which may therefore not be applicable to this small "footwear-related' change in step frequency reported above. The small spontaneous changes in step frequency associated with different footwear remain to be examined with respect to its impact on RE.

Therefore, the aim of this study was to examine if small enforced changes in step frequency, of a magnitude typically experienced by changing from CRS to MFW footwear types, will influence RE in trained males. A secondary aim was to provide practical advice for those using different footwear in an attempt to increase step frequency in the belief that it might enhance running performance.

\section{Methods}

\section{Participants}

Twelve male club-level runners with eight weeks prior minimal footwear experience (up to approx. $30 \mathrm{~km} /$ week) were recruited for the study (age, $41 \pm 9$ years; stature, $177.2 \pm 10.4 \mathrm{~cm}$; body mass, $\left.72.6 \pm 10.2 \mathrm{~kg} ; \dot{\mathrm{V}}_{2 \max }, 52.1 \pm 7.5 \mathrm{~mL} \cdot \mathrm{min}^{-1} \cdot \mathrm{kg}^{-1}\right)$. Participants typically ran 4-6 days per week with a mean weekly running distance of $52( \pm 11) \mathrm{km}$ at the time of the study. Participants were excluded if they had reported any running-related injuries in the last three months or had previous barefoot or minimalist running experience before the eight-week MFW transition. This transition has been previously reported [42]. All participants had previous experience with treadmill running. The participants gave informed consent at the beginning of testing. Ethical approval for this study was granted by the Dublin City University Research Ethics Committee. The present study meets the ethical standards required of this journal [18].

\section{Experimental design}

In a single testing session, subjects underwent two 6-min RE tests: one in MFW and one in CRS (balanced randomisation), during which the subject's naturally selected step frequency was recorded. For testing, foot size was measured and participants were provided with one pair of MFW (Vibram ${ }^{\circledR}$ Five Finger "KSO"; $150 \mathrm{~g}$ ), and a neutral CRS (Asics ${ }^{\circledR}$ "GEL-Cumulus” 2012; 400 g). The same RE tests were then repeated in both types of footwear (again randomised) but with enforced changes in step frequency. This was controlled by a metronome ("Mobile Metronome" Android software) set at the corresponding tempo of the opposite condition being tested (when participants ran in MFW, their recorded step frequency in CRS was enforced and vice versa), denoted "revSF" [reversed step frequency].

\section{Testing procedure}

Resting blood lactate (Lactate Plus, Nova Biomedical, Waltham, MA, USA) was sampled from the earlobe prior to the testing sessions. Respiratory data were measured using a Viasys Vmax Encore 299 online gas analysis system (Viasys Healthcare, Yorba Linda, CA, USA). The system was calibrated according to the manufacturer guidelines, including atmospheric pressure and temperature, before each new test. For this system, accuracy has been reported at $0.02 \%$ for oxygen measures, following a 15 -min warm-up period and calibrated within $5 \%$ of absolute operating range. A treadmill (Cosmed T170, Sport Med, Weil am Rhein, Germany) RE test was then conducted in the assigned footwear, either MFW or CRS in random order. Treadmill incline was set at $1 \%$ to account for air resistance [25]. Participants ran four trials lasting 6 min at $11 \mathrm{~km} \cdot \mathrm{h}^{-1}$, which has previously been considered an appropriate steady-state "endurance running" velocity [19]. At the end of each 6-min stage, participants were asked to stand to the side of the treadmill and a blood lactate sample was collected within $30 \mathrm{~s}$. At minute 5 in each stage, step frequency was collected by counting the left foot contact with the treadmill belt for $60 \mathrm{~s}$ duration. This procedure was repeated by the same investigator in each subject and also filmed for a second assessment and accuracy $\left(R^{2}=0.95\right.$; Sony HDR-CX210, 60FPS; Sony, San Diego, CA, USA). Rudimentary foot strike pattern (FSP) analysis was undertaken using this low-cost video camera, in which participants were filmed in the sagittal plane at foot level over a $15 \mathrm{~s}$ period during minute 4 of testing. The video footage was then used to assign 1 , 2, or 3 ( 1 = forefoot strike, 2 = midfoot strike, 3 = rearfoot strike) to the participants' foot strike pattern by the principal investigator using Dartfish video analysis software (Dartfish 5.5, Fribourg, Switzerland). A midfoot strike was assigned when there was no clear initial forefoot or heel contact. The validity of this method has been previously examined and highly correlated to the strike index $\left(R^{2}=.85\right)[1]$. The next test in the opposite footwear was started after $3 \mathrm{~min}$ of passive rest to allow the shoe type to be swapped over. After each shoe test was completed once, both tests were repeated after three minutes of passive recovery, but this time with the step frequency dictated by a metronome as reported above.

$\mathrm{A} \dot{\mathrm{V}} \mathrm{O}_{2 \text { max }}$ test was completed at the end of the day for subject characterisation. This involved a ramped treadmill protocol at $12 \mathrm{~km} \cdot \mathrm{h}^{-1}$ for a 5 -min warm-up before increasing to $14 \mathrm{~km} \cdot \mathrm{h}^{-1}$ at 
$1 \%$ incline. The incline was then increased every minute until volitional exhaustion and correlated with participants achieving a respiratory quotient (RQ) of 1.1 or above. Participants conducted this test in their own shoe choice. $\mathrm{VO}_{2 \max }$ was recorded as the highest breath-by-breath value averaged over $60 \mathrm{~s}$.

\section{Data processing}

The RE values were determined from the mean data over the last 2 min of each stage when participants had reached a true steadystate $\mathrm{VO}_{2}$. This was verified by less than a $1 \mathrm{mmol}$ increase in blood lactate (post-trial minus resting lactate) because this is considered well below maximal lactate steady state [38], and an RQ of less than $1.0[5]$.

\section{Data analysis}

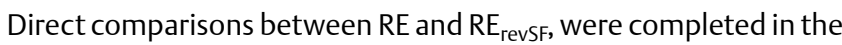

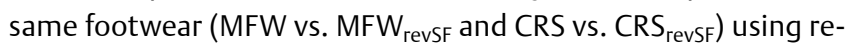
peated measures ANCOVA following establishment of parametric assumptions. Because it is possible that the foot strike pattern can influence $\mathrm{VO}_{2}$ values [16, 31], the foot strike pattern was included as a covariate in the analysis. Difference in step frequency between MFW and CRS was also examined with a paired t-test. Statistical significance was accepted at $\alpha \leq 0.05$ (Statistical Package for the Social Sciences data analysis software V22.0, SPSS Inc., Chicago, IL, USA).

Effect sizes are reported as Cohen's d [8]. The smallest standardised change that is considered meaningful was assumed to be an effect size of 0.20 for Cohen's d [8].

\section{Results}

No participants were excluded based on any visual slow component for submaximal $\dot{V}_{2}$ consumption, an increase in blood lactate of $>1 \mathrm{mmol}$ (mean change from resting $=0.44 \mathrm{mmol}$ ), or an RQ greater than 1.0. Because this was an acute study, no dropouts occurred due to injury or other reasons.

There was no difference whatsoever in the foot strike classification between the normal and reversed stride frequency for either shoe condition. For the MFW footwear, the distribution of foot strike patterns was 4 rearfoot strikes, 3 mid-foot strikes, and 5 forefoot strikes. For the CRS footwear, the distribution of foot strikes was 6 rearfoot strikes, 3 mid-foot strikes, and 3 forefoot strikes. The mean increase in step frequency for minimal footwear vs. conventional running shoes was $7.3 \pm 2.3$ steps per minute (3.9\% change; $\mathrm{p} \leq 0.001 ; 95 \% \mathrm{Cl}$ of difference [5.86 to 8.80]; MFW 184.2 \pm 10.6 vs. CRS $176.8 \pm 10.5$ steps per minute).

No differences were identified between $R E$ and $R E_{\text {revsF }}$ for minimal footwear when foot strike pattern was taken into account as a covariate ( $p=0.55$; $95 \% \mathrm{Cl}$ of difference [ -1.71 to 0.97 ]; Cohen's $\mathrm{d}=0.09 ; \mathrm{RE} 40.72 \pm 4.08 \mathrm{vs}$. $\left.\mathrm{RE}_{\mathrm{revSF}} 41.09 \pm 4.19 \mathrm{~mL} \cdot \mathrm{min}^{-1} \cdot \mathrm{kg}^{-1}\right)$, or conventional running shoes ( $p=0.55 ; 95 \% \mathrm{Cl}$ of difference $[-0.78$ to 1.37]; Cohen's d = 0.06; RE $42.04 \pm 4.68$ vs. $\mathrm{RE}_{\text {revSF }} 41.74 \pm 5.09$ $\left.\mathrm{mL} \cdot \mathrm{min}^{-1} \cdot \mathrm{kg}^{-1}\right)$. Differences are displayed in $>$ Fig. 1. Removing the foot strike pattern as a covariate factor did not influence the outcome in any way.

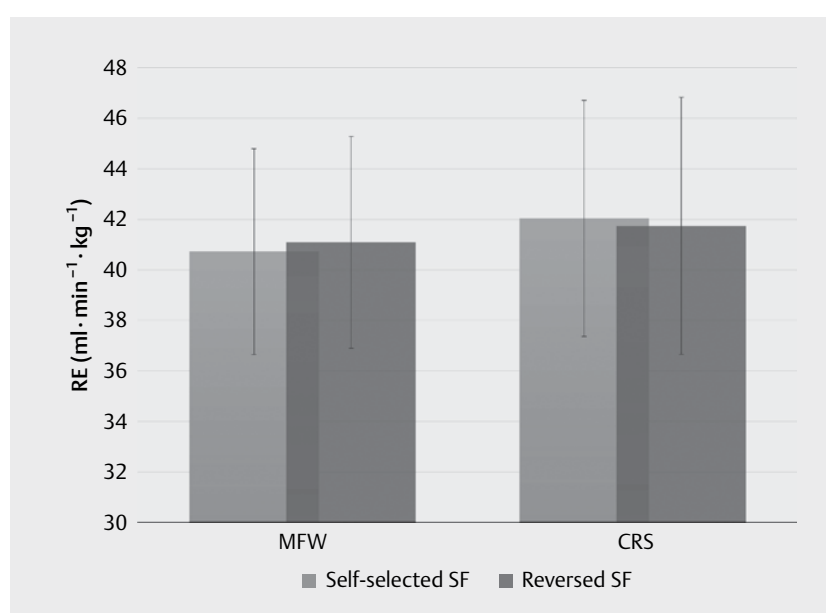

- Fig. 1 Differences in running economy (RE) when comparing the minimalist footwear (MFW) self-selected step frequency to reversed step frequency (SF), and the same comparison in conventional running shoes (CRS). No significant differences were observed. Error bars represent SD.

\section{Discussion}

The main finding of the present study is that changes in step frequency as a result of footwear condition ( $~ 4 \%)$ are not large enough to have any significant impact on RE, even when the foot striking pattern is controlled for in the analysis. Therefore, we reject the alternate hypothesis for this study. If RE changes are indeed associated with switching to MFW, this is most likely not due to the changes in step frequency that are typical of changing into this footwear.

The results of this study support previous work suggesting that step frequency is not an influencing factor for $\operatorname{RE}[2,9,22,44]$. Naturally selected step frequency has been found to be close to that which optimises running economy, with small deviations resulting in little or no change [6, 30]. To support this observation, more recent studies have deliberately reduced stride length by $3 \%$ (which will increase stride frequency) and have shown no change in RE $[12,28]$. A possible reason for this absence of any difference in $R E$ is most likely due to the magnitude of the changes to step frequency observed, which were found to be well below the changes imposed in experimentally imposed studies $[17,20]$. In one study, Franz, Wierzbinski and Kram [15] estimate that the $~ 3 \%$ greater step length observed during traditionally shod running when compared to barefoot would account for less than a $0.4 \%$ metabolic saving. As changes to step frequency in MFW were also in the region of $\sim 3 \%$ reported by Franz, Wierzbinski and Kram [15] in the barefoot condition, it could be suggested that the same conclusion applies. In the study by Hamill, Derrick and Holt [17], the authors noted that the preferred step frequency was the optimal for oxygen consumption. The authors also noted significantly greater oxygen consumption at $-10 \%,-20 \%$, and $+20 \%$ step frequency, but there was no significant difference at $+10 \%$. Therefore, the mean $+3.9 \%$ increase in step frequency in MFW in the present study is very small, and as such unlikely to cause any changes in RE, as observed here. 
In contrast to these findings, a significant negative correlation between RE and stride frequency ( $r=-0.61$ ) has been previously observed in 16 male long-distance runners [40]. In addition, Connick and Li (2014) have suggested that RE was optimised at a stride which was $2.9 \%$ ( $\pm 2.4 \%$ ) shorter than preferred [11]. In an earlier training study, 9 runners who presented with uneconomical freely chosen step lengths underwent a 3-week biofeedback programme to reduce step length by $10 \%$; a marked reduction in freely chosen step length as well as an improvement in RE was observed [29]. It is therefore possible that benefits to RE with changes in step frequency may only be apparent for those runners with low step frequency and/or uneconomical step length/frequency, and this should be examined further. Regardless, there appears to be contradictory research in the association between step mechanics and RE, with the current study confirming that no changes in RE are observed with small changes to step frequency.

One limitation of the current study is that the changes in step frequency were experimentally imposed in an acute study, and it is possible that acute, forced, unnatural changes to running mechanics may limit any potential benefits to RE [27,42]. However, this theory needs to be investigated further, as well as long-term training studies on self-optimisation of RE with changes in running mechanics. Finally, it would have been beneficial to work with a larger sample size, so that groups could be divided according to foot strike patterns in order to establish if there is any interaction between foot strike and step frequency changes in RE. This question could be examined in future research with a large cohort of runners with varied running mechanics.

\section{Conclusion}

Changes in step frequency as a result of footwear condition ( $4 \%$ ) do not have any significant effect on RE. Therefore, changes in RE associated with MFW are most likely due to other factors not examined in this study.

\section{Acknowledgements}

None

\section{Conflicts of Interest}

The authors have received a donation of footwear for the present study from Vibram ${ }^{\circledR}$ (Milan, Italy). No honoraria or conditions were attached to this donation, and the company has no direction or involvement in the research. All authors report no other conflicts of interest.

\section{References}

[1] Altman AR, Davis IS. A kinematic method for footstrike pattern detection in barefoot and shod runners. Gait Posture 2012; 35 : 298-300

[2] Arampatzis A. Influence of the muscle-tendon unit's mechanical and morphological properties on running economy. J Exp Biol 2006; 209: 3345-3357
[3] Bellar D, Judge LW. Effect of training in minimalist footwear on oxygen consumption during walking and running. Biol Sport 2015; 32: 149-154

[4] Bonacci J, Saunders PU, Hicks A, Rantalainen T, Vicenzino B, Guglielmo T, Spratford W. Running in a minimalist and lightweight shoe is not the same as running barefoot: A biomechanical study. Br J Sports Med 2013; 47: 387-392

[5] Brooks GA, Fahey TD, White TP, Baldwin KM. Exercise Physiology: Human Bioenergetics and Its Applications. Sydney: McGraw-Hill; 2000

[6] Cavanagh PR, Williams KR. The effect of stride length on oxygen uptake during distance running. Med Sci Sports Exerc 1982; 14: 30-35

[7] Cheung RT, Ngai SP. Effects of footwear on running economy in distance runners: A meta-analytical review. J Sci Med Sport 2016; 19: 260-266

[8] Cohen J. Statistical Power Analysis for the Behavioral Sciences. 2nd ed. Mahwah, NJ: Lawrence Earlbaum Associates; 1988

[9] Concejero S], Granados C, Irazusta J, Letona BI, Lili Z], Tam N, Gil SM. Differences in ground contact time explain the less efficient running economy in North African runners. Biol Sport 2013; 30: 181-187

[10] Conley DL, Krahenbul GS. Running economy and distance running performance of highly trained athletes. Med Sci Sport Exerc 1980; 12: 357-360

[11] Connick MJ, Li FX. Changes in timing of muscle contractions and running economy with altered stride pattern during running. Gait Posture 2014; 39: 634-637

[12] Craighead DH, Lehecka N, King DL. A novel running mechanic's class changes kinematics but not running economy. I Strength Cond Res 2014; 28: 3137-3145

[13] Divert C, Mornieux G, Freychat P, Baly L, Mayer F, Belli A. Barefoot-shod running differences: Shoe or mass effect? Int J Sports Med 2008; 29: 512-518

[14] Esculier JF, Dubois B, Dionne CE, Leblond J, Roy JS. A consensus definition and rating scale for minimalist shoes. J Foot Ankle Res 2015; 8: 42

[15] Franz JR, Wierzbinski CM, Kram R. Metabolic cost of running barefoot versus shod: Is lighter better? Med Sci Sports Exerc 2012; 44: 1519-1525

[16] Gruber AH, Umberger BR, Braun B, Hamill J. Economy and rate of carbohydrate oxidation during running with rearfoot and forefoot strike patterns. J Appl Physiol 2013; 115: 194-201

[17] Hamill J, Derrick TR, Holt KG. Shock attenuation and stride frequency during running. Hum Mov Sci 1995; 14: 45-60

[18] Harriss D, Macsween A, Atkinson G. Standards for ethics in sport and exercise science research: 2018 update. Int J Sports Med 2017; 38: $1126-1131$

[19] Hatala KG, Dingwall HL, Wunderlich RE, Richmond BG. Variation in foot strike patterns during running among habitually barefoot populations. PLoS One 2013; 8: 4-9

[20] Heinert LD, Serfass RC, Stull GA. Effect of stride length variation on oxygen uptake during level and positive grade treadmill running. Res $Q$ Exerc Sport 1988; 59: 127-150

[21] Hryvniak D, Dicharry J, Wilder R. Barefoot running survey: Evidence from the field. J Sport Heal Sci 2014; 3: 131-136

[22] Kyrolainen $\mathrm{H}$, Belli A, Komi PV. Biomechanical factors affecting running economy. Med Sci Sports Exerc 2001; 33: 1330-1337

[23] Lucia A, Esteve-Lanao J, Oliván J, Gómez-Gallego F, San Juan AF, Santiago C, Pérez M, Chamorro-Viña C, Foster C. Physiological characteristics of the best Eritrean runners-exceptional running economy. Appl Physiol Nutr Metab 2006; 31: 530-540

[24] Lussiana T, Fabre N, Hébert-Losier K, Mourot L. Effect of slope and footwear on running economy and kinematics. Scand J Med Sci Sport 2013; $23: 246-253$ 
[25] Jones $\mathrm{M}$, Jonathan $\mathrm{H}$, Doust A. A $1 \%$ treadmill grade most accurately reflects the energetic cost of outdoor running. J Sports Sci 1996; 14: 321-327

[26] Messier SP, Cirillo KJ. Effects of a verbal and visual feedback system on running technique, perceived exertion and running economy in female novice runners. J Sports Sci 1989; 7: 113-126

[27] Moore IS. Is there an economical running technique? A review of modifiable biomechanical factors affecting running economy. Sport Med 2016; 46: 793-807

[28] Moore IS, Jones A, Dixon S. The pursuit of improved running performance: Can changes in cushioning and somatosensory feedback influence running economy and injury risk? Footwear Sci 2014; 6: $1-11$

[29] Morgan D, Martin P, Craib M, Caruso C, Clifton R, Hopewell R. Effect of step length optimization on the aerobic demand of running. J Appl Physiol 1994; 77: 245-251

[30] Nigg B, Enders H. Barefoot running - some critical considerations. Footwear Sci 2013; 5: 1-7

[31] Perl DP, Daoud Al, Lieberman DE. Effects of footwear and strike type on running economy. Med Sci Sports Exerc 2012; 44: 1335-1343

[32] Ridge ST, Standifird T, Rivera J, Wayne Johnson A, Mitchell U, Hunter I. The effect of training in minimalist running shoes on running economy. J Sport Sci Med 2015; 14: 643-647

[33] Rothschild C. Running barefoot or in minimalist shoes. Strength Cond ] 2012; 34: 8-17

[34] Saunders PU, Pyne DB, Telford RD, Hawley JA. Reliability and variability of running economy in elite distance runners. Med Sci Sports Exerc 2004; 36: 1972-1976

[35] Schumacher YO. Commentary on "The key to top-level endurance running performance: a unique example”. Br J Sports Med 2008; 42 : 174-174
[36] Sobhani S, Bredeweg S, Dekker R, Kluitenberg B, van den Heuvel E, Hijmans J, Postema K. Rocker shoe, minimalist shoe, and standard running shoe: A comparison of running economy. J Sci Med Sport 2014; 17: 312-316

[37] Squadrone R, Rodano R, Hamill J, Preatoni E. Acute effect of different minimalist shoes on foot strike pattern and kinematics in rearfoot strikers during running. J Sports Sci 2015; 33: 1196-1204

[38] Svedahl K, Maclntosh BR. Anaerobic threshold: The concept and methods of measurement. Can J Appl Physiol 2003; 28: 299-323

[39] Tanji F, Shirai Y, Tsuji T, Shimazu W, Nabekura Y. Relation between 1,500-m running performance and running economy during high-intensity running in well-trained distance runners. J Phys Fit Sport Med 2017; 6: 41-48

[40] Tartaruga MP, Brisswalter J, Peyré-Tartaruga LA, Ávila AOV, Alberton $\mathrm{CL}$, Coertjens M, Cadore EL, Tiggemann CL, Silva EM, Kruel LFM. The relationship between running economy and biomechanical variables in distance runners. Res Q Exerc Sport 2012; 83: 367-375

[41] Warne JP, Kilduff SM, Gregan BC, Nevill AM, Moran KA, Warrington GD. A 4-week instructed minimalist running transition and gait-retraining changes plantar pressure and force. Scand J Med Sci Sport 2014; 24: 964-973

[42] Warne JP, Moran KA, Warrington GD. Eight weeks gait retraining in minimalist footwear has no effect on running economy. Hum Mov Sci 2015; 42: 183-192

[43] Warne JP, Warrington GD. Four-week habituation to simulated barefoot running improves running economy when compared with shod running. Scand J Med Sci Sport 2014; 24: 563-568

[44] Williams KR, Cavanagh PR. Relationship between distance running mechanics, running economy, and performance. J Appl Physiol 1987; 63: 1236-1245 